DOI: $10.47456 / k r k r . v 1 i 5.32538$

\title{
Como uma estrela guia: o PIBID na visão de professoras em início de carreira de Corumbá-MS
}

As a guide star: Corumbá's fresh graduate teachers' view on PIBID

Tatiane Zabala Gomes

Edelir Salomão Garcia

Márcia Regina do Nascimento Sambugari

\begin{abstract}
Resumo: Este artigo apresenta a pesquisa que investigou o impacto do Programa Institucional de Bolsas de Iniciação à Docência (PIBID) na vida de professoras iniciantes, ex-PIBIDianas do curso de Pedagogia do Câmpus do Pantanal (CPAN), da Universidade Federal de Mato Grosso do Sul (UFMS) em Corumbá, Mato Grosso do Sul. Numa abordagem qualitativa, na pesquisa de campo utilizou-se de entrevista com roteiro semiestruturado com quatro professoras em início de carreira, egressas do PIBID Subprojeto Pedagogia/CPAN/UFMS. A análise dos dados apontou que a participação no PIBID alterou de forma positiva a vida das ex-bolsistas, ao trazer experiências construtivas em suas vidas tanto como acadêmicas, quanto na vida profissional, contribuindo na constituição docente ao articular os conhecimentos e saberes desenvolvidos no PIBID. Ressalta-se, portanto, o quanto programas como o PIBID, que fomentam a reflexão e prática da docência na relação universidade e escola são imprescindíveis na vida dos futuros professores.
\end{abstract}

Palavras chave: Formação Docente. Pedagogia. Atuação Docente

Abstract: This article presents the research which looked into the impact of the "Institutional Teaching Initiation Scholarship Program" (PIBID) in the life of recently graduated teachers, ex-PIBIDians of the Pedagogy's course at the Mato Grosso do Sul's University (UFMS), Pantanal's Campus (CPAN) in Corumbá. In a qualitaty approach, the field research applied a semi-structured scripted interview with four fresh graduate teachers, egressed from the PIBID. The data analysis indicated that the participation in PIBID has had a positive change in the ex scholarship holders' lives, bringing constructive experiences not only in their academic lives, but also professional ones, contributing to the teachers' constitution by articulating the knowledge and understandingness developed during PIBID. It stands out, therefore, how much programs that promote the praxis between university and school, like PIBID, are indispensable in the life of future teachers.

Keywords: Teacher Training. Pedagogy. Teachers' Performance.

\section{Introdução}

O Programa Institucional de Bolsas de Iniciação à docência (PIBID), vinculado à Coordenação de Aperfeiçoamento de Nível Superior (CAPES) consiste em "[...] uma iniciativa para o aperfeiçoamento e a valorização da formação de professores para a educação básica", a fim de "[...] promover a inserção dos estudantes no contexto das escolas públicas desde o início da sua formação acadêmica para que desenvolvam atividades didático- 
pedagógicas sob orientação de um docente da licenciatura e de um professor da escola" (CAPES, 2008).

O programa surge da necessidade de valorização da profissão docente no Brasil, buscando valorizar à docência nas universidades de todo país e, sobretudo, incentivar os estudantes das licenciaturas a atuarem na Educação Básica. Neste aspecto André (2012, p. 125) destaca que:

[...] um diferencial nesse programa é a concessão de bolsas não só a alunos e professores das universidades, mas também a professores de escolas públicas que acompanham as atividades dos bolsistas no espaço escolar, atuando assim como coformadores no processo de iniciação à docência, em articulação com o formador da universidade.

A autora observa também que o programa foi inicialmente:

[...] direcionado apenas às instituições federais de ensino superior, atendendo cerca de 3 mil bolsistas em 2007, nas áreas de Física, Química, Biologia e Matemática para o ensino médio, o PIBID se expandiu rapidamente, incluindo universidades públicas estaduais, municipais e comunitárias, abrangendo todas as licenciaturas (ANDRÉ, 2012, p. 126).

De acordo com o decreto $n^{\circ} 7.219 / 2010$ (BRASIL, 2010) em seu art. $3^{\circ}$, o programa teve como objetivos:

I - incentivar a formação de docentes em nível superior para a educação básica; II - contribuir para a valorização do magistério; III - elevar a qualidade da formação inicial de professores nos cursos de licenciatura, promovendo a integração entre educação superior e educação básica; IV inserir os licenciandos no cotidiano de escolas da rede pública de educação, proporcionando-Ihes oportunidades de criação e participação em experiências metodológicas, tecnológicas e práticas docentes de caráter inovador e interdisciplinar que busquem a superação de problemas identificados no processo de ensino-aprendizagem; V - incentivar escolas públicas de educação básica, mobilizando seus professores como coformadores dos futuros docentes e tornando-as protagonistas nos processos de formação inicial para o magistério; e VI - contribuir para a articulação entre teoria e prática necessárias à formação dos docentes, elevando a qualidade das ações acadêmicas nos cursos de licenciatura (BRASIL, 2010, p. 4).

Dessa maneira, além de ter um caráter de valorização profissional e de conhecimento da área, o programa assume o caráter de inserção do bolsista 
no contexto da instituição escolar com a finalidade de conhecer o ambiente, sendo acompanhado de perto, não apenas pela Universidade, mas também pelo corpo docente da escola que o auxiliará nos desafios encontrados ao longo de sua inserção no cotidiano da escola.

Fetzner e Souza (2012) destacam que o PIBID oportuniza a vivência da iniciação no campo da docência em diálogo com a formação teórica oportunizada na universidade, precisando que os campos estejam em posição de troca de saberes. Para Silva (2013), a diferença inicia desde a forma de atuação, sendo que o PIBID se caracteriza como uma atividade opcional, enquanto que o estágio se caracteriza como uma atividade de caráter obrigatório e ressalta que há:

[...] outras particularidades como o período de contato que o licenciando tem com a sala de aula [...]; o momento em que a docência surge na formação do aluno (o Pibid busca alunos a partir do segundo semestre de curso, o Estágio ocorre nos semestres finais da graduação); a imersão no cotidiano da comunidade escolar (os pibidianos avaliavam os alunos, ministravam aulas, elaboravam material, participavam de coordenações). O principal elemento diferenciador é o caráter de pesquisa-ação do Pibid (SILVA, 2013, p. 23).

Para a autora, o caráter de pesquisa-ação do PIBID se justifica porque aprecia os conhecimentos científicos que são produzidos pelos bolsistas, ao invés de serem apenas os consumidores da pesquisa realizada por outros. Dessa forma, os mesmos têm a oportunidade de transformar as salas de aula em que permanecem por um período duradouro, em objetos de pesquisa.

Para realizarmos o estudo aqui apresentado, primeiramente fizemos um levantamento de artigos na biblioteca eletrônica da Scientific Eletronic Library Online (SciELO) utilizando o descritor "PIBID", no qual foi possível verificarmos a relevância da temática ao localizarmos, num período compreendido entre 2014 a 2020, um total de 56 artigos, sendo 48 publicados em periódicos brasileiros, quatro em Portugal, dois no México, um na Argentina e um no Chile.

Ao filtrarmos as publicações referentes ao PIBID em cursos de Pedagogia identificamos quatro artigos, dos quais dois tratam de memoriais de formação durante do PIBID, tendo o de Alburquerque, Frison e Porto (2014) 
focalizado as aprendizagens realizadas por uma acadêmica do curso de licenciatura em Pedagogia por meio de um memorial reflexivo, enquanto bolsista PIBID. Enquanto que o artigo de Bergamaschi e Almeida (2013) apresenta a pesquisa realizada a partir da narrativa de memória de 14 estudantes de Pedagogia bolsistas PIBID.

Freitas (2014) aborda o cotidiano do PIBID, analisando as dimensões psicossociais do processo de participação e formação de um grupo de alunos da licenciatura de Pedagogia, Filosofia e Ciências Sociais, junto ao projeto Interdisciplinar-Pedagogia, no PIBID/CAPES-UFPR.

Yasmin, Campos e Catanante (2016) investigaram o impacto do PIBID subprojeto Pedagogia para 25 bolsistas do curso de Pedagogia de duas instituições de Dourados-MS, por meio da análise de relatório e fichas avaliativas das atividades realizadas, a fim de buscar verificar se o programa incentivou buscar exercer futuramente a docência. As autoras apontam que a participação no PIBID:

[...] expandiu os conhecimentos das acadêmicas acerca das possibilidades e dos limites da profissão. Apesar da relação instável, a rejeição inicial sofrida no período de início do programa, resultante do histórico de práticas aligeiradas de estágios, cedeu seu lugar a sentidos de parceria, de cumplicidade e de respeito. O tempo de permanência na instituição e a construção de vínculos foram fundamentais para construir uma relação de confiança entre escola e universidade (YASMIN; CAMPOS; CATANANTE, 2016, 43-44).

A leitura e análise desses artigos nos mostrou que as pesquisas não têm como foco o professor em início de carreira, contudo, o contato com esses estudos permitiu delinear a nossa pesquisa, buscando responder algumas indagações tais como: que mudanças são propiciadas no percurso de um acadêmico durante sua graduação, após a sua inserção no PIBID? Qual o papel do PIBID para a formação inicial do professor?; De que maneira a metodologia do PIBID, com suas reuniões, professores supervisores e professores coordenadores, auxiliam na formação dos alunos?

Dessa maneira, a pesquisa buscou investigar o impacto do PIBID na vida de professoras iniciantes, ex-PIBIDianas do curso de Pedagogia do 
Câmpus do Pantanal (CPAN), da Universidade Federal de Mato Grosso do Sul (UFMS) localizado em Corumbá, Mato Grosso do Sul.

A seguir apresentamos o caminho metodológico percorrido, bem como os resultados e discussões trazendo a importância do PIBID na formação inicial das professoras iniciantes, bem como para a sua constituição docente.

\section{Metodologia}

A realização desse estudo pautou-se na abordagem qualitativa por meio da pesquisa de campo, que segundo Fonseca (2002 apud GERHARDT; SILVEIRA, 2009) se caracteriza por investigações em que é realizada a coleta de dados junto a pessoas. Contamos, portanto, com a participação de quatro professoras e participaram do PIBID durante 0 seu curso de Pedagogia/CPAN/UFMS.

Para Huberman (1995), o início da carreira é considerado os três primeiros anos de atuação, caracterizado por um estado de "sobrevivência" e "descoberta", onde sobrevivência é o "choque do real" da confrontação inicial com a complexidade da situação profissional, a distância entre os ideais e as realidades cotidianas da sala de aula, dificuldade com a relação pedagógica e transmissão de conhecimento, entre outros. E a descoberta é o entusiasmo inicial, a exaltação por estar em situação de responsabilidade, assim como sentir-se parte do corpo profissional. Isso torna fundamental uma ação de fortificação do período de início de carreira, para que as situações do estado de sobrevivência não ultrapassem o estado de descoberta da profissão docente.

Para proceder a pesquisa de campo utilizamos a entrevista como instrumento para a produção de dados, por ser uma técnica de interação social em que uma das partes busca obter dados e a outra se apresenta como fonte de informação (GERHARDT; SILVEIRA, 2009).

A entrevista foi organizada por meio de um roteiro semiestruturado com a finalidade de obter diferentes respostas a mesma pergunta, possibilitando, assim, verificar as recorrências, bem como as singularidades nos depoimentos. Em conformidade com as normas éticas de pesquisa com seres humanos, as participantes assinaram o Termo de Consentimento Livre e Esclarecido 
(TCLE), aceitando participar do estudo, bem como garantindo o sigilo pessoal. Dessa maneira, as participantes estão identificadas por Professora 1; Professora 2; Professora 3; e Professora 4.

Após a realização da entrevista, que foi gravada, partimos para a transcrição e organização dos depoimentos sob forma de quadro, agrupando nos seguintes eixos: (i) importância/relevância do PIDID para a formação inicial; (ii) metodologia do subprojeto; e (iii) contribuições para a atuação docente, cujas análise e discussões constam a seguir.

\section{Resultados e discussões}

Antes de iniciamos a discussão dos dados situamos que o PIBID está presente no curso de Pedagogia/CPAN/UFMS desde o 2011 por meio da seleção do Edital n'. 001/2011/CAPES e aprovação do Subprojeto que contou com um supervisor, um coordenador de área e oito bolsistas participantes dentro de uma escola da rede estadual de ensino de Corumbá, MS. De acordo com o subprojeto, a escola foi selecionada por dois motivos: o primeiro foi devido ao resultado do Índice de Desenvolvimento da Educação Básica (Ideb), e o segundo pela possibilidade de desenvolver uma ação integrada entre o curso de Pedagogia e Matemática (lócus onde este grupo já estava atuando) do CPAN.

Para dar continuidade, o curso concorreu a um novo edital (Edital $n^{\circ}$ 061/2013/CAPES), tendo o grupo ampliado nessa nova proposta, passando a atender duas escolas da rede pública, sendo uma escola da rede municipal e a outra da rede estadual de ensino, contando com 23 acadêmicos bolsistas distribuídos em dois subgrupos: um formado por 11 acadêmicos bolsistas e outro por 12 acadêmicos bolsistas; dois coordenadores de área, um para cada escola e quatro professores supervisores, sendo dois em cada escola.

Com uma metodologia dinâmica, havia o acompanhamento nas salas, no qual eram evidenciadas as dificuldades, anseios e, esses levados para a Universidade, junto ao professor coordenador de área e os professores supervisores em reuniões para acompanhamento de projeto, oficinas e em 
sessões de estudo. E, foi neste subprojeto o que as quatro professoras iniciantes participaram.

A proposta consistiu em desenvolver atividades em salas de alfabetização de $1^{\circ}$ ano ao $5^{\circ}$ ano tendo como um dos objetivos firmar parceria com o professor regente da sala, para buscar novas metodologias de ensino que possibilitem a superação das metodologias usuais, que, em sua maioria, acabam por não auxiliar o aluno no processo de inserção à leitura e escrita.

Sobre a alfabetização e letramento, Soares (2004) assevera que na aprendizagem inicial da língua escrita existem sérios reflexos ao longo de todo o Ensino Fundamental, sendo necessário rever os quadros referenciais que estão sendo utilizados e os processos de ensino que tem predominado nas salas de aula. Por esses reflexos serem duradouros, perduram pela vida escolar do aluno, e por isso são necessárias a análise e a autoanálise das práticas educativas exercidas.

As quatro professoras em início de carreira, sujeitos desse estudo, são mulheres com 21, 24, 44 e 55 anos. Participaram do Subprojeto do PIBID Pedagogia/CPAN/UFMS entre dois a três anos; tendo uma professora participado por três anos, e três participaram por dois anos no programa. No que diz respeito ao tempo na atuação profissional, a duração foi de três meses a dois anos no exercício docente, o que caracteriza o início de carreira conforme destacado por Huberman (1995).

Para compreender o impacto do programa na vida das ex-bolsistas e atuais professoras da rede de ensino, foi realizada a entrevista, buscando que refletissem sobre o papel do PIBID em sua formação inicial e a contribuição do mesmo para a sua atuação docente.

Ao serem indagadas sobre a importância do PIBID em sua graduação, as Professora 1 e Professora 3 levam em consideração o fato de que dentro do programa elas puderam aliar a teoria aprendida na Universidade com a prática exercida na sala em que eram bolsistas; e a Professora 2 e Professora 4 estimam que o programa auxiliou na aprendizagem dos conteúdos dentro da universidade, no âmbito do curso. 
"E, ai se não fosse o PIBID, sabe, para me mostrar que tudo o que a gente vê na teoria é aplicável na prática, eu não teria tido essa noção [...] E isso ai foi essencial no período da faculdade [...]" (Professora 1. Entrevista).

"O PIBID... é... Ele me auxiliou na minha aprendizagem também. Porque tudo o que eu vivia dentro de sala de aula, no meu contato direto em sala de aula, todos os meus questionamentos, todas as minhas dúvidas em relação ao ensino-aprendizagem, eu levava para as minhas professoras na universidade" (Professora 2. Entrevista).

"O PIBID na minha graduação foi de suma importância, pois pude fazer a correlação da teoria com a prática, assimilando assim melhor os conteúdos, e toda a aprendizagem adquirida ao longo do curso, fazia mais sentido [...] proporcionou uma AUTONOMIA que até então eu desconhecia" (Professora 3. Entrevista).

"[...] a gente discutia algumas coisas, algumas concepções que a gente tinha né, ai a gente ia para a escola e víamos outras situações e acabávamos levando pra lá, para tentar discutir, pensar numa possibilidade de melhora que poderíamos fazer [...] isso em qualquer matéria" (Professora 4. Entrevista).

Percebemos, por meio da análise dos depoimentos que as participantes, através do PIBID refletiam questões que se formavam dentro de uma sala de aula em que elas faziam parte e eram partícipes da formação dos alunos, mas, acima de tudo, conseguiam pensar sobre a própria formação, levando indagações para o âmbito universitário, e compartilhando suas vivências para ambientes além das reuniões somente com PIBIDianos.

Quando as participantes citam o fato de o PIBID auxiliá-las no processo da práxis, podemos citar as considerações de Medeiros e Cabral (2006) que apontam a práxis como algo que necessita de um posicionamento crítico da realidade e o contexto que o professor está inserido. Nesse sentido, há necessidade de compreendermos o professor como intelectual, crítico e transformador, conforme defendido por Giroux (1997) ao ressaltar que, se o professor carrega essas características, ele se reconhece como sujeito capaz de promover mudanças e também criar condições de seus alunos se tornarem também críticos e transformadores.

Nesse contexto, o programa parece ter contribuído quando, inclusive citado pelas entrevistadas, os PIBIDianos conseguem levar os questionamentos das práxis para suas salas de aulas da universidade, tendo a 
possibilidade de se formarem com bases fundadas do processo vivido e discutido com base nos referenciais teóricos, podendo assim, contar com a ajuda dos professores da universidade para ampliarem os seus fundamentos e refletir a teoria na prática e a prática com fundamentos teóricos.

No que diz respeito a relevância do programa na formação inicial, as Professora 1, Professora 2 e Professora 4 destacam que o programa as auxiliou na busca de mais conhecimento para lidar com uma sala de aula, a repensar a sua prática ainda dentro da universidade.

\begin{abstract}
"Durante esse período da universidade ele contribuiu da seguinte forma: o que é que eu preciso buscar mais, o que eu preciso aprender mais em questão de teoria? [...] a gente precisava pensar como iríamos trabalhar [...] como que eu ia auxiliar a professora se eu não sabia? Então assim, a gente foi discutindo, indo nos grupos, fomos fazendo as oficinas que fomos aprendendo a como levar todos esses conhecimentos e a buscar mais, para aplicar na sala de aula junto com o professor" (Professora 1. Entrevista).

"Ela me ajudou em relação ao ensino-aprendizagem e na minha prática também. Porque é muito fácil você querer fazer diferente. É muito fácil você colocar toda culpa da professora. Criticar a prática da professora em sala de aula, só que quando você se vê no lugar da professora, é que você vê como é difícil" (Professora 2. Entrevista).

"Nossa, foi muito importante. Porque quando eu fazia estágio eu estava meio perdida. A gente estuda tanta coisa né, que eu não tinha um rumo ainda. As aulas que eu planejava com as meninas durante o estágio nas intervenções, elas não tinham um seguimento ainda fixo, depois que eu comecei o PIBID, que a gente conheceu o trabalho, eu tive a oportunidade de conhecer o método que eu trabalho, o sociolinguístico. Foi o PIBID que deu um norte..." (Professora 4. Entrevista).
\end{abstract}

Enquanto que a Professora 3 aponta que o PIBID fortaleceu sua escolha pela docência.

"O PIBID na minha formação inicial só me fez fortalecer a certeza de estar no caminho certo a seguir como profissional. É a hora que conseguimos ver e decidir se realmente é o que queremos para nós, pois atuando no PIBID, constatamos que ser professor, é uma tarefa árdua sem dúvida, porém gratificante, onde podemos observar e acompanhar o desenvolvimento dos alunos" (Professora 3. Entrevista). 
Os depoimentos das professoras são pertinentes com as discussões sobre o processo de constituição do se fazer docente. É possível perceber o quanto esse processo é feito de forma sólida quando há uma participação no PIBID, onde as professoras sempre enfatizam o fato de que durante o curso, o programa instigou-as a procurar mais das teorias para trabalhar efetivamente com as crianças.

Para Pimenta e Ghedin (2005) é preciso em primeiro lugar instigar os professores a terem uma cultura de análise de suas práticas, a partir da problematização das mesmas e da realidade. Em segundo lugar, reforçar a importância da Universidade na formação, com processos formativos que tomem a realidade escolar como parte integrante desse processo.

Sendo assim, levando em consideração os autores, podemos inferir que participar do PIBID faz o aluno refletir a sua prática à luz de teorias apreendidas no cotidiano universitário, portanto, o aluno não precisará ser exaluno para então conseguir analisar a sua prática, já que ele adquire experiências a partir do programa.

Acerca da contribuição da escola onde realizou o PIBID para a formação inicial, todas as professoras relataram serem muito gratas pela recepção que tiveram dentro das escolas, obtendo apoio da direção, da coordenação e dos professores, exceto a Professora 3 que, ao se envolver com os alunos da sala e ter uma percepção diferenciada, evidenciou certo estranhamento e resistência por parte da professora regente. A Professora 4 ressalta a importância da experiência do PIBID para acostumar-se a rotina escolar, ao tempo de serviço dentro da escola.

"As duas escolas abriram as portas de verdade pra gente, eles de verdade se importaram com o que a gente estava aprendendo, eles tinham respeito pela gente como se fossemos professoras mesmo sabe, e eles faziam os alunos terem isso também. $E$ nós participamos de todos os momentos importantes pra escola, um que eu posso citar foi a festa junina que a gente participava ativamente, o desfile de aniversário de Corumbá, então assim, em todos os momentos. [...]. Eu tive acesso à direção [...] eu tive acesso a coordenação, a sala de professores, que a gente podia conversar com outros professores, trocar experiências, a sala de aula, então assim, em todos os momentos, em todos os espaços, a escola 
contribuiu pra gente aprender e atuar" (Professora 1. Entrevista).

"A primeira sala de aula que ingressei, percebi um certo "ciúme" da professora [...] Exagerei na minha autonomia, onde olhei a realidade de alguns alunos levando a dificuldade deles adiante, [...] Acabei saindo e passando para a outra turma. [...] Como tudo nunca é um mar de rosas, aos poucos percebi algumas situações de conflito [...] Só que esse momento foi também primordial para meu aprendizado [...]" (Professora 3. Entrevista).

"Você acaba vivenciando a rotina escolar, né! Você tem horário, você sabe qual o horário que você tem que chegar. Não é igual na faculdade, você não queria assistir uma aula e você chegava na segunda, na terceira aula. $E$ aqui não [referindo-se à escola], a gente acaba pegando o ritmo de escola mesmo. Mas eu acho que foi importante, foi bom tanto pra gente que teve a oportunidade de vivenciar isso quanto pros professores também" (Professora 4. Entrevista).

Nesse sentido, podemos perceber a aproximação das PIBIDianas com o contexto escolar e seus diferentes espaços, onde puderam ter contato com outros professores e adquirir conhecimento da realidade vivida. Essa realidade fica em evidência na fala da Professora 1 que cita a participação ativa dela até mesmo nas datas comemorativas, onde geralmente apenas professores regentes são solicitados para fazer parte da organização.

Podemos inferir que a escola não entra apenas com o papel de "abrir as portas" para os acadêmicos, pois, ao abrir as portas, ela assume o papel de fazer parte da formação dos mesmos, além de possibilitar a formação continuada dos professores atuantes da sua instituição. Pois ao receber os alunos PIBIDianos os professores regentes, e supervisores, de certa forma, participam das atividades propostas pelo programa, e, nesse contexto, passam a repensar a escola e suas práticas (CAPES, 2009).

Com relação a metodologia do subprojeto, quando questionadas a respeito das reuniões que ocorriam no espaço da universidade, percebe-se claramente o padrão estipulado pelo PIBID/Pedagogia/CPAN. Todas as participantes relataram que havia duas reuniões semanais, sendo uma oficina para elaboração de material e a outra reunião consistia na discussão da realidade escolar, momentos de desabafos e trocas de conhecimento entre 
PIBIDianos e discussão teórica para subsidiar as práticas e elaboração de projetos.

"[...] fazíamos as construções dos cartazes que a gente ia precisar levar, e as reuniões em que era um momento em que a gente falava como tinha sido, o que a gente tinha presenciado, os conflitos surgidos, tanto que a gente falava que era uma terapia esses momentos em que nós nos reuníamos, porque a gente botava nossas aflições, e o PIBID ele trás muitas aflições pra gente, [...] então assim, a gente ficava com muitos conflitos né, na sala de aula, levava pro grupo de discussão, a professora levava muitos textos relacionados a didática e era discutido tudo isso" (Professora 1. Entrevista).

"Tinha as reuniões, geralmente era uma vez por semana e até duas vezes por semana. Geralmente era uma tarde de discussões, então ali nós participávamos para contar pra professora se nós estávamos recebendo apoio da escola, se as crianças realmente estavam tendo algum avanço, não só na parte de estudos, mas também no convívio social" (Professora 2. Entrevista).

Podemos verificar que todas as reuniões tiveram um propósito, seja para confeccionar os materiais necessários na escola e/ou planejamentos, seja para discutir textos que auxiliam na compreensão em relação à escola e como lidar com os problemas que nela se encontram. Esse processo em grupo ajuda na reflexão e socialização de saberes dos futuros professores, já que com isso podem ter acesso à perspectiva do outro sobre seus questionamentos, bem como o suporte teórico para o desenvolvimento da prática profissional.

Nessas reuniões de acompanhamento ocorriam discussões sobre os acontecimentos que enriquecem e favorecem o crescimento intelectual do grupo, sempre com a ajuda de referenciais teóricos (sessões de estudo) que dão base para que as experiências dentro da sala de aula seja um momento propicio para a autoavaliação da futura prática que cada um exercerá, além de fortalecer a relação teoria e prática. Essas reflexões pautadas em referenciais teóricos levam os PIBIDianos elaborarem novas propostas de ensino bem como elaboração materiais pedagógicos que subsidiam o processo ensino aprendizagem.

Para Bergamaschi e Almeida (2013), nesse processo não há protagonismo individual, já que um bolsista aprende com o outro por meio do 
exercício de docência, fazendo-os pensar a profissão de professor que tradicionalmente é refletida solitariamente e, mais importante ainda, os fazem pensar no quanto o trabalho coletivo oportuniza o crescimento de todos e exige comprometimento com a proposta educativa.

A respeito do convívio com a professora supervisora dentro da escola, as participantes revelaram que elas faziam o papel de apoio na instituição, dando Ihes suporte para materiais, resolução de problemas na escola e, até mesmo, a inclusão das bolsistas no âmbito escolar, nos diferentes ambientes que ali se encontra.

"[...] toda essa parte de apoio de material, ela fazia acolhida, ela fazia com que nós ficássemos na sala dos professores junto com eles, coisa que nós não fazíamos, nós ficávamos num pátio. Dificilmente entravamos" (Professora 2. Entrevista).

"Eu tive duas professoras ma-ra-vi-lho-sas [falando pausadamente] [...] eu estava até a pouco tempo comentando com algumas colegas do trabalho o quanto a professora [fala o nome da professora] auxiliou positivamente na minha prática. [...] E uma coisa que a professora [repete o nome] me ensinou, eu lembro disso todos os dias [...], que ela fala que o professor, ele tem que chegar em casa, lá no final do expediente e pensar o que ele fez de ruim que ele poderia melhorar, e o que ele fez de bom que ele poderia melhorar, e isso é uma coisa que eu aplico na minha prática, todos os dias que eu chego em casa eu penso sobre a minha prática" (Professora 1. Entrevista).

A análise desses depoimentos sinaliza que as professoras supervisoras tiveram um papel importante na formação das bolsistas, seja integrando-as no contexto escolar, seja ensinando-as refletir sobre a prática docente diariamente. Para Bergamaschi e Almeida (2013), a ideia de envolver professores no exercício da docência com a formação inicial cria vínculos geracionais, pois os estudantes que aspiram a docência podem ter nesses professores em atuação uma referência, uma inspiração para sua futura profissão.

Em relação ao auxílio da coordenadora de área na universidade, foi unânime a gratidão no sentimento de cada uma, em questão de obterem dentro da faculdade uma professora que pensava na formação docente e questionava as alunas posturas que são necessárias dentro de uma instituição de ensino, as ensinava ainda dentro da faculdade a serem professoras, partia de 
exemplos vividos dentro do PIBID para ensinar-lhes como trabalhar e viver a docência.

\begin{abstract}
"Nossa, o auxilio dela era quase que integral com a gente, né [risos] porque tudo que acontecia, por mais que tinha a coordenadora que acompanhava na escola, o meu contato maior sempre foi com a coordenadora de lá, porque a gente vivia lá na faculdade né. Então era mais fácil... [...] $E$ lá na faculdade era diferente, a professora era nossa [...] coordenadora [...] Mas assim, no processo em si, ela foi de suma importância. Porque ela cobrava da gente poder estudar, pra gente poder encontrar um caminho certo, e ela orientava. Porque tem professor que faz assim "esse aqui não tá certo, então melhor você pegar e fazer assim", dava pronto. Ela não, ela instigava você a pensar em uma possibilidade. Então ela dialogava com você, ela ouvia e falava: "se isso não tá certo, então por onde você acha que deve ir?" Não dava a resposta pronta, porque acho que isso às vezes atrapalha, dar pelo mais fácil. Ela fazia você colocar a cabeça pra pensar e ver uma possibilidade de trabalhar" (Professora 4. Entrevista).

"[...] dava todo apoio. Sempre deu todo apoio [...]" (Professora 2. Entrevista).
\end{abstract}

Nesse contexto, foi perceptível o amparo das professoras coordenadoras sobre os problemas encontrados pelas PIBIDianas, pois foram elas que guiaram as acadêmicas dentro do programa. O professor coordenador, ao dialogar com os bolsistas e fazer com que elas refletissem sobre os problemas encontrados e buscassem soluções parece hoje refletir na atuação docente, ou seja, elas conseguem buscar alternativas aos problemas encontrados no seu dia-a-dia no ambiente da sala de aula no momento de sua atuação profissional.

A respeito da constituição docente dentro do PIBID e em que as exalunas sentem a diferença na atuação da atual profissão após participarem do programa, houve respostas diversas, mas com o mesmo sentido de conseguirem se constituir docente mesmo estando na fase inicial da carreira, na fase de aprender a ser professor - sendo, e, assim conquistarem uma postura, um método, um norte e refletir sobre tudo que estavam vivendo.

"Ele me ajudou assim, a escola apesar dela impor o tradicional, é ela quem vai querer organizar como é que você vai trabalhar em sala de aula, mas você em sala de aula, você é responsável de como você vai atuar, é você que vai fazer o seu 
método. [...] Mas eu procurei trabalhar com a alfabetização e letramento sem desassociar as duas, é assim que eu soube trabalhar. Consegui pensar na alfabetização e letramento no PIBID, e consigo trabalhar só desse jeito" (Professora 2. Entrevista).

"Eu acho que ele me deu um norte, o PIBID me possibilitou vivenciar algumas coisas que me fez pensar o que eu não queria quando eu tivesse atuando [...] ele me possibilitou durante a universidade a ter uma postura como educadora e foi me moldando, foi me ajudando a achar um caminho, me fez pensar o que eu quero pra mim e o que eu não, quero como eu tenho que trabalhar com as crianças... [...] se não fosse o PIBID, eu acho que eu não teria a estrutura que eu tenho hoje" (Professora 4. Entrevista).

Nessa reflexão feita pelas PIBIDianas percebemos um sentimento que elas tiveram uma formação diferenciada, pois, o programa as possibilitou uma vivência que os demais acadêmicos do curso não tiveram. Essa questão pode ser verificada no depoimento da Professora 3 que enfatizou ter saído do patamar de espectadora e plateia do contexto escolar, para tornar-se protagonista.

\begin{abstract}
"A partir do momento que ingressei no PIBID, deixei de ser mera espectadora. Sai da plateia e passei a ser também protagonista de um cenário do âmbito educacional. [...] Ampliou a minha visão de se ter a consciência plena da importância de assumir, de 'vestir a camisa' dessa profissão docente, desafiadora, mas acima de tudo, gratificante. Essa trajetória é de uma responsabilidade imensurável [...] O mergulho é profundo no que se refere a trabalho em equipe, no convívio com os discentes, docentes e todos envolvidos na instituição escolar, na reflexão sobre a minha prática, como me constituo educadora, na humildade e sabedoria de reconhecer os erros, aprender com eles e aprimorar sempre. Me reafirmo cada vez mais com a autonomia adquirida nesse cotidiano escolar" (Professora 3. Entrevista).
\end{abstract}

A professora 1 ressaltou o fato de que se não fosse o PIBID, ela não seria a docente que ela enxerga ser hoje, frisando que se lembra do programa e de todos os ensinamentos que o mesmo trouxe para sua constituição profissional.

"Eu me sentia como professora, eu vivi a docência no PIBID, coisa que eu não vivi no estágio, sabe? O PIBID ele tinha a preocupação não só de jogar a gente dentro da escola, mas de olhar para esses alunos que estavam ali dentro. [...] $\mathrm{E} O$ 
principal: o PIBID não dura 17 (dezessete) aulas como o estágio, ele dura 0 ano inteiro! [...] O professor lá da universidade ele te procura, ele procura o professor, procura a escola. Então isso é o diferencial, eu acho que se não fosse o PIBID eu não ia conseguir ser a pessoa, professora, que eu sou hoje, sabe? Quando eu começo a entrar naquela crise, na confusão de algumas coisas, eu lembro do PIBID. Porque em muitas "terapias" que a gente tinha com a professora coordenadora, ela dizia que esses momentos fazem parte, que a gente tem que viver isso mesmo para dar aquela balançada para voltar ao normal depois, coisa que eu não tive no estágio. [...] Eu tive a oportunidade de ter o primeiro choque de realidade como um docente, ainda na minha formação, e isso pra mim foi inigualável" (Professora 1. Entrevista).

Essas posições parecem evidenciar os resultados dos estudos de Bergamaschi e Almeida (2013) em que o PIBID promoveu ao aluno a se constituir como professor, colaborando com a formação do recém docente.

Para Sant'anna, Marques e Costa (2015), um curso de formação de professores deve construir saberes capazes de entender o contexto social em que está inserido e que dê prioridade a realidade em que o aluno se insere. Destacam ainda que para isso acontecer, é preciso dar instrumentos ao aluno por meio de atividades de ensino, pesquisa e extensão, teorias e métodos de investigação que os levem a ler criticamente a realidade, podendo assim construir o seu conhecimento e aprendizado a partir de situações reais, problematizando sua prática profissional a fim de aperfeiçoar a sua prática.

Esses argumentos parecem ter constituído o projeto PIBID de pedagogia em estudo, pois os acadêmicos ao se tornarem bolsistas do programa em referência, foram levados a pensar sobre a escola, a realidade escolar e a procurar meios de lidar com a trama que a envolve de tal forma que a formação inicial parece ter se constituído como elemento da identidade docente e, que de certa forma, fará com que eles sejam profissionais que sempre refletirão sobre sua prática na busca de melhorar sua atuação, ou seja, estarão em constante lapidação.

\section{Considerações finais}

Buscamos com esse texto trazer as discussões relativas ao PIBID na vida de ex-alunas que fizeram parte dele, sendo possível constatar o quanto a 
participação no programa alterou de forma positiva a vida das ex-bolsistas, pois todas informaram que o programa trouxe experiências construtivas em suas vidas como acadêmicas e, ao sair da universidade esta formação tem auxiliado no campo de trabalho, o impacto foi ainda maior já que puderam usar das práticas que tiveram durante a participação no PIBID em suas atuais práticas.

Entendemos, ainda, por meio da análise dos relatos das professoras sobre o funcionamento do programa no curso de Pedagogia/CPAN/UFMS o quanto o programa não atingiu apenas a formação inicial das acadêmicas, mas proporcionou aos professores em exercício uma reflexão de sua prática em diálogo com as acadêmicas, bem como com as professoras supervisoras e a coordenadora de área.

O programa parece atender muito mais que a formação inicial de futuros professores, mas com a reflexão do docente em exercício demonstrando que esse programa acaba por cumprir múltiplas finalidades essenciais para a docência, para a escola e para a qualificação do ensino.

É importante ressaltar o quanto programas como o PIBID, que fomentam a reflexão e prática da docência na relação universidade e escola são imprescindíveis na vida do universitário de licenciatura, uma vez que verificamos a ausência de práticas durante a graduação, mesmo existindo estágios e matérias que desenvolva práticas pedagógicas, pois parece não fornecer subsídios necessários para a formação docente, pois as mesmas ocorrem em um prazo delimitado de tempo o que não permite fazer que se analise o contexto de forma ampla e aprofundada.

Temos clareza dos rumos de instabilidade e finalidades que o programa tem sofrido a partir de 2015 com os cortes orçamentários e em sua metodologia, mas a pesquisa realizada nos faz acreditar na perspectiva de Ball (1983) do potencial que as instituições têm de subverter as políticas e programas, e, portanto, a importância em socializar resultados de pesquisas sobre o PIBID como os aqui apresentados, a partir do Subprojeto desenvolvido no âmbito do curso de Pedagogia/CPAN/UFMS. 


\section{Agradecimento}

Esse trabalho contou com o apoio da Universidade Federal de Mato Grosso do Sul (UFMS) e da Coordenação de Aperfeiçoamento de Pessoal de Nível Superior - Brasil (CAPES) - Código de Financiamento 001.

\section{Referências}

ALBUQUERQUE, M. P.; FRISON, L. M. B.; PORTO, G. C. Memorial de formação escrito no decorrer da prática docente: aprendizagens sobre alfabetização e letramento. Revista brasileira de estudos pedagógicos. Brasília, v. 95, n. 239, p. 73-86, 2014. Disponível em: https://www.scielo.br/pdf/rbeped/v95n239/a05v95n239.pdf. Acesso em 20 jul. 2020.

ANDRE, M. Políticas e programas de apoio aos professores iniciantes no Brasil. Cadernos de Pesquisa. São Paulo, v. 42, n.145, p. 112-129, 2012. Disponível em: https://www.scielo.br/pdf/cp/v42n145/08.pdf. Acesso em: 12 jul. 2020.

BALL, S. J. La micropolítica de la escuela: hacia uma teoria de la organización escolar. Barcelona: Paidós, 1989.

BERGAMASCHI, M. A.; ALMEIDA, D. B. Memoriais escolares e processos de iniciação à docência. Educar em revista. Belo Horizonte, v. 29, n. 2, p. 15-41, jun., 2013. Disponível em: https://www.scielo.br/pdf/edur/v29n2/02.pdf. Acesso em: 18 jul. 2020.

BRASIL. Decreto n. 7.219, de 24 de junho de 2010. Dispõe sobre o Programa Institucional de Bolsa de Iniciação à Docência - PIBID e dá outras providências. Diário oficial da União. Brasília: Casa Civil da Presidência da República, Seção 1, 25/6/2010, p. 4, 2010.

COORDENAÇÃO DE APERFEIÇOAMENTO DE NÍVEL SUPERIOR. Pibid Programa Institucional de Bolsa de Iniciação à Docência. Quarta, 03 de setembro de 2008. Última Atualização: Sexta, 06 Março 2020. Disponível em: http://www.capes.gov.br/educacao-basica/capespibid/pibid. Acesso em: 20 jul. 2020.

FREITAS, M. F. Q. A pesquisa participante e a intervenção comunitária no cotidiano do Pibid/CAPES. Educar em Revista. Curitiba, Editora UFPR, n. 53, p. 149-167, jul./set., 2014. Disponível em: https://www.scielo.br/pdf/er/n53/10.pdf. Acesso em: 20 jul. 2020.

GERHARDT, T. E.; SILVEIRA, D. T. Métodos de pesquisa. Universidade Aberta do Brasil - UAB/UFRGS. Curso de Graduação Tecnológica. Planejamento e Gestão para o Desenvolvimento Rural da SEAD/UFRGS. Porto Alegre: Editora da UFRGS, 2009. Disponível em: 
http://www.ufrgs.br/cursopgdr/downloadsSerie/derad005.pdf. Acesso em: 20 jul. 2020.

GIROUX, H. Teoria crítica e resistência em educação: para além das teorias de reprodução. Petrópolis: Vozes, 1997.

HUBERMAN, M. O ciclo de vida profissional dos professores. In: NÓVOA, A. (Org.). Vidas de Professores. Porto: Porto Editora, 1995, p. 31-61.

MATEUS, E. F. Um esboço crítico sobre "parceria" na formação de professores. Educação em revista. Belo Horizonte, v. 30, n. 3, p. 355-384, set., 2014. Disponível em: https://www.scielo.br/pdf/edur/v30n3/v30n3a16.pdf. Acesso em: 20 jul. 2020.

MEDEIROS, M. V.; CABRAL, C. L. de O. Formação docente: da teoria à prática, em uma abordagem sócio-histórica. Revista E-Curriculum. São Paulo, v. 1, n. 2, junho de 2006.

PIMENTA, S. G, GHEDIN, E. (org.). Professor reflexivo no Brasil: gênese e crítica de um conceito. São Paulo: Cortez, 2005.

SANT'ANNA, Paulo Afranio; MARQUES, Luiz Otávio Costa. Pibid Diversidade e a Formação de Educadores do Campo. Educação \& realidade. Porto Alegre, v. $40, \quad$ n. 3 , p. 725-744, 2015 . Disponível em: https://www.scielo.br/pdf/edreal/2015nahead/2175-6236-edreal-45795.pdf.

Acesso em 20 jul. 2020.

SILVA, K. D. Pibid x estágio obrigatório: a importância da pesquisa-ação. 2013. 70f. Monografia em Letras (Português do Brasil como Segunda Língua Licenciatura). Universidade de Brasília - UNB. Brasília - DF, 2013. Disponível em: $\quad$ https://bdm.unb.br/bitstream/10483/7224/1/2013 KarineDouradoSilva.pdf Acesso em 20 jul. 2020.

SOARES, M. Alfabetização e letramento: um tema em três gêneros. São Paulo: Contexto, 2004.

YAMIN, G. A.; CAMPOS, M. I; CATANANTE, B. R. "Quero ser professora": a construção de sentidos da docência por meio do Pibid. Revista brasileira de estudos pedagógicos. Brasília, v. 97, n. 245, p. 31-45, 2016. Disponível em: https://www.scielo.br/pdf/rbeped/v97n245/2176-6681-rbeped-97-245-00031.pdf. Acesso em: 20 jul. 2020.

\section{Sobre os autores}

\section{Tatiane Zabala Gomes}

tatianezg@gmail.com

Graduada em Pedagogia pela Universidade Federal de Mato Grosso do Sul (UFMS). Mestranda em Educação do Programa de Pós-Graduação em Educação/UFMS, do Câmpus do Pantanal (CPAN). Professora da rede municipal de ensino da Prefeitura de Corumbá, MS. 


\section{Edelir Salomão Garcia}

edelir.salomao@gmail.com

Doutora em Educação Escolar pela Universidade Estadual Júlio de Mesquita Filho (UNESP), da Faculdade de Ciências e Letras de Araraquara (FCLAr). Mestre em Educação pela Universidade Metodista de Piracicaba. Professora Associada Aposentada da UFMS/CPAN.

\section{Márcia Regina do Nascimento Sambugari}

marcia.sambugari@ufms.br

Doutora em Educação pelo Programa de Estudos Pós-Graduados em Educação: História, Política, Sociedade (EHPS) da Pontifícia Universidade Católica de São Paulo (PUC-SP). Mestre em Educação Escolar pela UNESP/FCLAr. Professora Associada da UFMS/CPAN, com atuação no curso de Pedagogia e no Programa de Pós-Graduação em Educação (PPGE/CPAN). 